Original Research Paper

\title{
Effect of Fibre Content on Compressive and Flexural Properties of Coconut Fibre Reinforced Epoxy Composites
}

\author{
${ }^{1}$ Jasem G. Alotaibi, ${ }^{1}$ Ayedh Eid Alajmi, ${ }^{2}$ Belal F. Yousif and ${ }^{3}$ Nbhan D. Salih \\ ${ }^{1}$ Department of Automotive and Marine Engineering Technology, Public Authority for Applied Education and Training, Kuwait \\ ${ }^{2}$ Faculty of Health, Engineering and Sciences, University of Southern Queensland, Toowoomba, QLD, Australia \\ ${ }^{3}$ Multimedia University, Malaysia
}

Article history

Received: 25-03-2020

Revised: 14-05-2020

Accepted: 15-06-2020

Corresponding Author:

Belal F. Yousif

Faculty of Health, Engineering and Sciences, University of

Southern Queensland,

Toowoomba, QLD, Australia

Email: belalyousif@yahoo.com

\begin{abstract}
Coconut fibre reinforced polymer composites are gaining popularity in the field of engineering due to the many benefits that come with them such as low cost of production, easy fabrication, enhanced strength compared to other polymer composites. Of late, there has been an increase in the use of composites that are naturally based because they have many benefits. In line with this, the current research is focused on the mechanical properties of coconut fiber reinforced epoxy composites. The effect of the fibre content on the flexural and compressive characteristics of the epoxy composites was investigated. Chemical treatment of the coconut fibres was performed using $50 \%$ bleaching concertation. The composites were fabricated in random orientations withe fibre length of $10 \mathrm{~mm}$ as recommended by the literature. Scanning Electron Microscopy (SEM) was used to examine the fractured surfaces. The main findings are that the increase in the volume fraction of the coconut fibre in the epoxy composites increases the flexural and compressive strengths. SEM showed that the main failure mechanisms were brittle nature in the epoxy regions and pullout and breakage of fibres in the coconut region.
\end{abstract}

Keywords: Natural Fibers, Mechanical Properties, Epoxy, Content Percent

\section{Introduction}

Fibre reinforced composites have been applied in various applications due to their many benefits like their cost of production which is low, they are easy to fabricate and they are stronger compared to other polymer resins that are neat. Reinforcing the polymers can either be synthetic or be natural. Synthetic fibre for instance glass, carbon and so forth has high specific strength, however, their applications are limited because their cost of production is higher compared to the natural fibres. Of late, there is an increase in the interest of the natural fibre composites because of the many benefits that come with them. Modern materials science suggests that the analysis of fracture tolerance is useful in improvement of components mechanical performance as reported by (Hedayati and Vahedi, 2017). Due to this reason, more research has been directed at coconut fibre with the aim of manufacturing value-added goods. The purpose of this research paper is to study the effect of fibre content on coconut oil fibre reinforced epoxy composites.

In this research, the composite is made from the combination of epoxy resin and coconut fibre and then fabricated by use of a compression moulding technique. Some of the parameters that are of the significant essence in this study are inclusive of the fraction of the fibre volume that is found in the material, the curing time plus the capacity of the compression load that is applied during the process of fabrication.

The use of coconut fibre-reinforced epoxy composites relies on the mechanical properties of the coconut. Previous studies have shown that these properties that belong to the organic fibres are influenced by various factors for instance behaviour that is stress strained of the fibre plus the phases of the matrix, the distribution of the fibre in the composite and the orientation of the fibre. Moreover, the parameters of the fabrication process by which the composite is produced can also influence the process of production. Therefore, it is important to appreciate the level of the impacts that form the previous composite.

Since polymer matrix composites have appeared to be useful materials that can take over after the conventional materials such as metals and woods, the demand to carry out an analysis of their tribological tendency has been amplified. This section contains the tribological behaviour of the coconut fibre reinforced 
composites with regards to friction and wear. The section shall touch on the impacts of the various operational parameters along with material parameters on the rate of wear and the friction behaviour of the coconut-reinforcedpolymer-composites (Omrani et al., 2016).

This study shows that operational parameters such as the sliding velocity, the load, the slide distance or length and the material parameters such as fibre orientation, length of the fibre, the volume fraction of the fibre and the filler content all have a great impact on the tribological behaviour of the composite material. The rate of wear of the coconut fibre- reinforced composites is controlled by addition of proper quantities of the filler content along with the orientation of the fibre (Omrani et al., 2016).

There are several studies of fibre orientation such as parallel, anti-parallel, normal and normal that have been listed by researchers. Researchers have joined the coconut fibre with a polymer resin and conducted studies on their tribological properties. For instance, coconut fibre with epoxy resin, with polyester reinforcement and all this combination end up with the result that a normal orientation leads to the minimum rate of wear whereas the random orientation provides a great effect (Supian et al., 2018).

Evaluation of the physical properties, the mechanical properties along with the flammability properties of the coconut-reinforced composites. Four levels of the coconut fibre content were used in the following concentration: 75 , $80,85,90$ and $95 \%$. While increasing the content of the coconut, it was discovered that the strength of the internal bond of the composites reduced. Nonetheless, the flexural strength, the hardness and the tensile strength of the composites enhanced with the increase of the content of the coconut fibre up to $60 \%$. Adding $5 \%$ of the coconut content enhanced the tensile properties of the of the matrix composites. It was discovered that the tensile strength of the composites that are reinforced with $5 \%$ of the coconut fibres portrayed a better performance in terms of features than other fibres (Bongarde and Shinde, 2014).

\section{Materials}

\section{A-Matrix Materials}

Experimental, analytical and numerical approaches should be followed when investigation of flexural properties of coconut fibre reinforced epoxy composites is considered. Due to their high reliability, experimental methods are the most appropriate ones for achieving the desired results for such a purpose, (Hedayati and Vahedi, 2018) and (Hedayati and Vahedi, 2017). The most used matrices are the polymer matrices among the various kinds of matrix materials due to the various benefits that come with them such as cost-effectiveness, exceptional room temperature properties as well as their ease of fabrication with a lower tool rate. Polymer matrices are thermoplastic, or they are thermosetting and the most used resins for thermosetting are polyester, phenolics, epoxy and so forth. The epoxy resins stand out since they are majorly used in most of the composites that are superior due to their benefits like good adhesion properties with various types of fibres, they have superior mechanical properties along with electrical properties coupled with a good performance at high temperatures. Moreover, they are having low shrinkage properties when they are cured and they possess good chemical resistance. Because epoxy resins have many advantages above other thermoset polymers, they have been chosen as the matrix material in this research paper. Epoxy resin is classified under the epoxide family.

\section{B-Fibre Preparation}

The organic fibre is pulled out of the husk of a coconut fruit. The husk is made of coconut fibre plus a tissue which is corky known as pith. It is made of water, little amounts of solids that are soluble and also fibres. Due to the elevated levels of the lignin, the coconut is very strong in comparison to other organic fibres. As the demand for efficient fuel goes higher, composites that are coconut based can be used in many applications such as in the automobile industry and in the railway coaches along with the public transport system buses. A great opportunity exists in the fabrication of composites that are coconut based, they are applied widely in the construction of boards and blocks such as wood and flooring tiles. They have the advantage of low density, they are biodegradable and they are cheap as well. It also has benefits such as high chemical resistance, high tensile strength, cheaper cost and insulating properties. Figure 1 shows the raw fibres obtained from the supervisor which has been supplied by a natural fire company. The fibres were cut into $10 \mathrm{~mm}$ length of fibres. The fibres were washed with tap water and then chemical treatment is conducted.

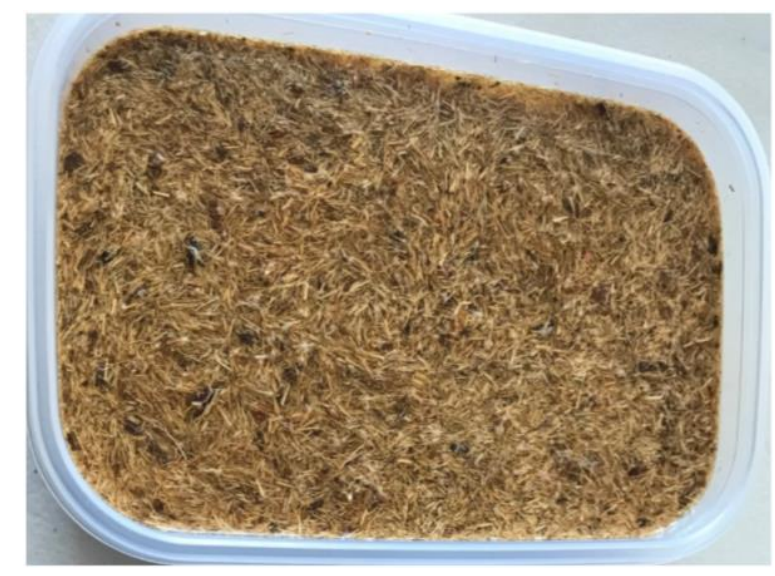

Fig. 1: First stage of the fibre preparation and cutting the fibres 


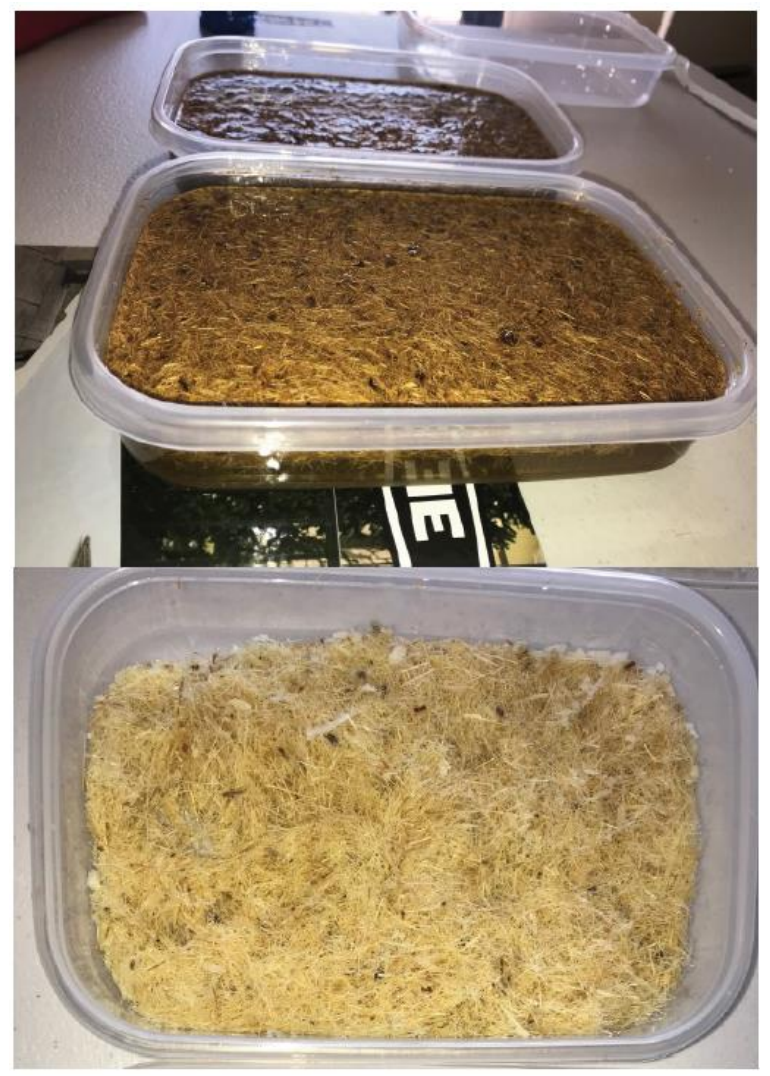

Fig. 2: chemical treatment of the coconut fibres

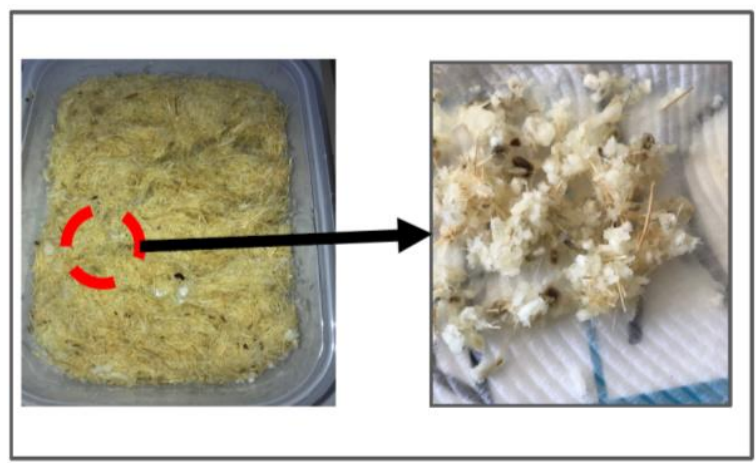

Fig. 3: fibres photo after $24 \mathrm{~h}$ bleaching treatment

The chemical treatment was conducted by using $50 \%$ concentrated solution of bleach and tap water, Fig. 2 . Previous and recent bleaching methods were used to treat natural fibres as reported by (Hamidon et al., 2019) and Espinach et al. (2018).

The prepared fibres were immersed in a $50 \%$ bleach solution for $24 \mathrm{~h}$ at room temperature. After $24 \mathrm{~h}$ soaking, the fibres were washed with tap water and by naked eyes, the following was noticed:

- The colour of the fibres became very light and the brownish colour vanished
- Waxy debris was formed and aggregated as the small ball as can be seen in Fig. 3

- There is no destruction to the fibres structure. However, SEM will be conducted to confirm this

\section{Composite Fabrication}

The coconut group is gathered from local sources and are used as reinforcement. The epoxy resin is bought from suppliers it is the matrix material. The ratio of the low temperature that is used in curing the epoxy resin and the respective hardener is 10:1 As recommended by weight. A mould with the following dimensions is used in casting the composite slabs; $210 * 210 * 40 \mathrm{~mm}^{3}$. The coconut fibres are then mixed together with the epoxy resin by use of mechanical stirring. The preparation of the composites takes place with three various loading of fibre along with four varying lengths as the composite content of the fibre is kept constant that is $20 \mathrm{wt} \%$ by use of a simple technique of lay-up. The mixture is then poured into several moulds that conform to the specifications of the different conditions of testing along with the standards of characterization. Each cast of every composite is then preserved under a $20 \mathrm{~kg}$ load for twenty- four hours before it taken away from the cavity of the mould. Appropriate dimensions of the specimens are cut in order to be used in physical tests and also mechanical tests. D 638M will be adapted in the experiment as recommended recently by Indra Reddy et al. (2018). Therefore, a mould is developed as shown in Fig. 4 which will be used in the fabrication of the composites.

The mould shown in the above figure was coated with a thin layer of wax to ease the release of the samples after the fabrication. In addition, the separation between the upper and lower part of the mould was done by using a non-stick paper in-between the tow part surfaces as can be seen in Fig. 5. The next step was to place the required amount of fibres in the cavity of the mould while the mixture of the epoxy and hardener was ready to be used. After the fibres were carefully and uniformly distributed in the cavity, the epoxy mixture was poured in the cavity slowly to avoid any generation of bubbles. After the samples were prepared in the mould, they have been cured at room temperature of $25^{\circ} \mathrm{C}$ for $24 \mathrm{~h}$ as recommended by the manufacturer. The curing process, the samples were carefully removed from the mould and extra edges were removed. Three samples were prepared for each composite at various fibre volume fractions. Four types of composites were prepared as pure epoxy, 10\% Coconut/Epoxy, 30\% Coconut/Epoxy and $40 \%$ Coconut/Epoxy. Due to the cold weather in Toowoomba, some of the samples failed due to the poor curing process which required repetition of the fabrication process. 


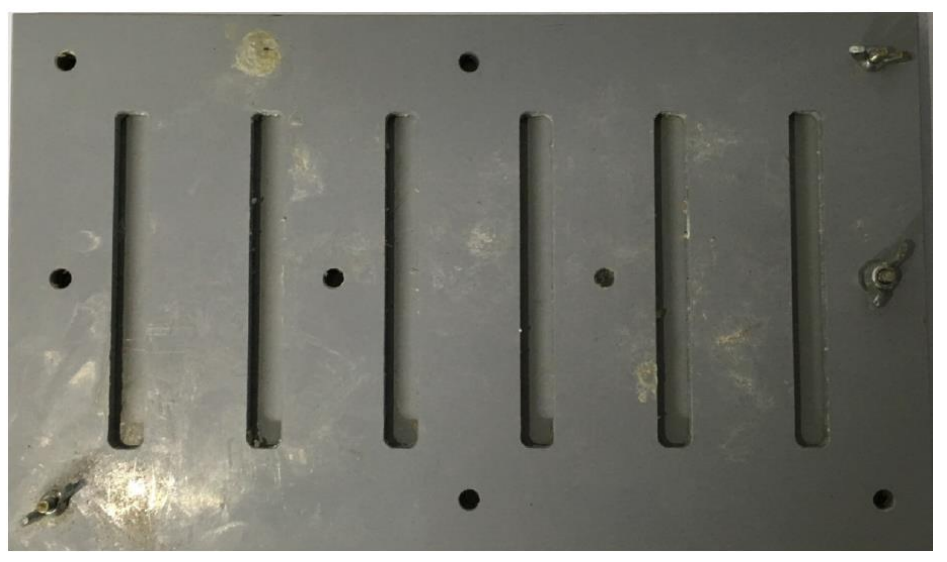

Fig. 4: Flexural mould

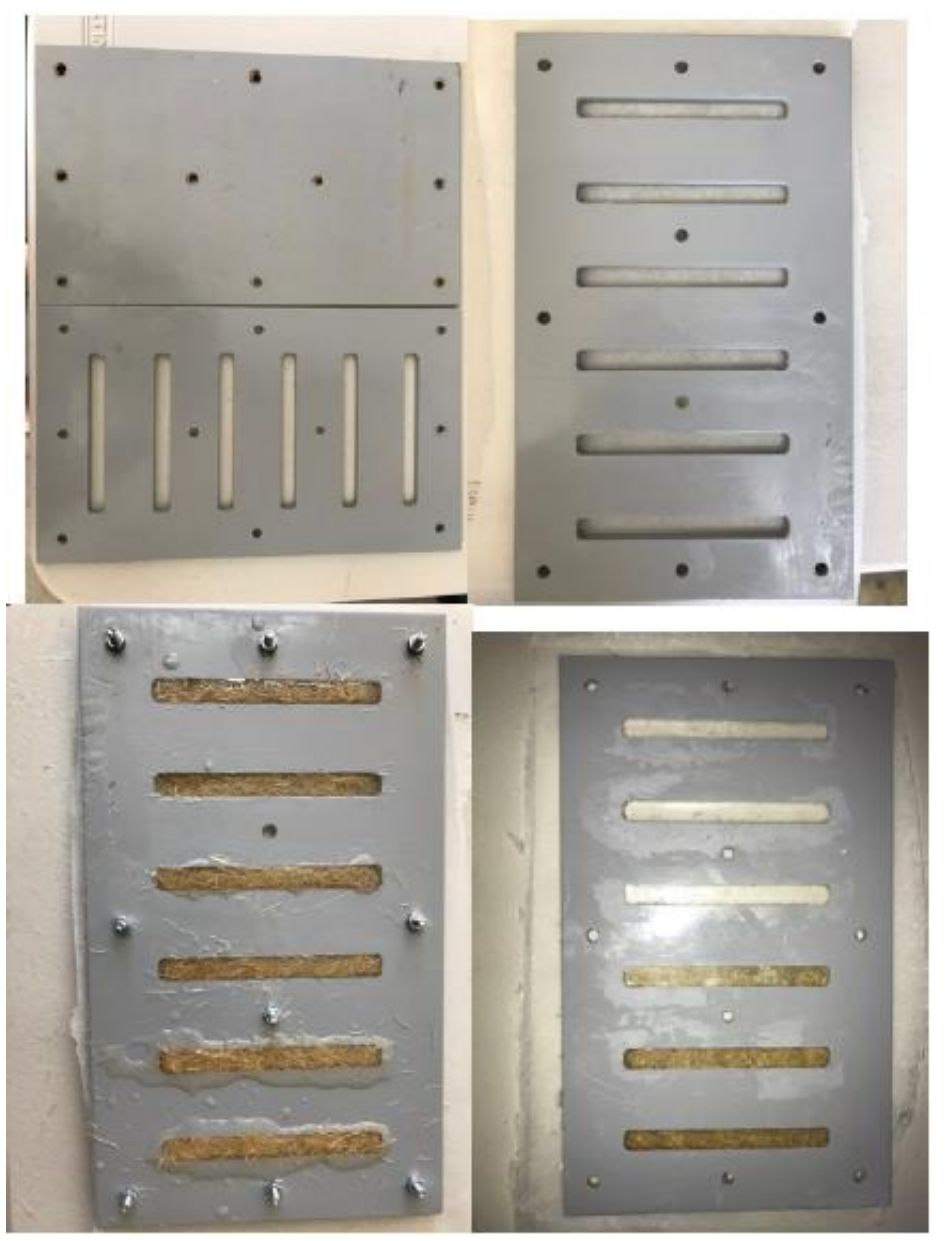

Fig. 5: fabrication process of the epoxy samples

\section{Tests for Mechanical Properties}

In line with the test standards, the composites' flexural and compressive samples were fabricated by as described in the previous section to be tested using a universal testing machine (Fig. 6). In this experiment, the velocity is considered to be $2 \mathrm{~mm} / \mathrm{min}$ with a maintained span of $40 \mathrm{~mm}$. flexural testing was performed using three-point bending configuration as shown in Fig. 7 each test was repeated more than three times and the average of the closest three values of the strength was determined for both compressive and 
flexural strengths. The compressive testing was used using a universal tensile machine as shown in Fig. 8. similar to the flexural testing, for each set of test, more than three samples were used for the same test.

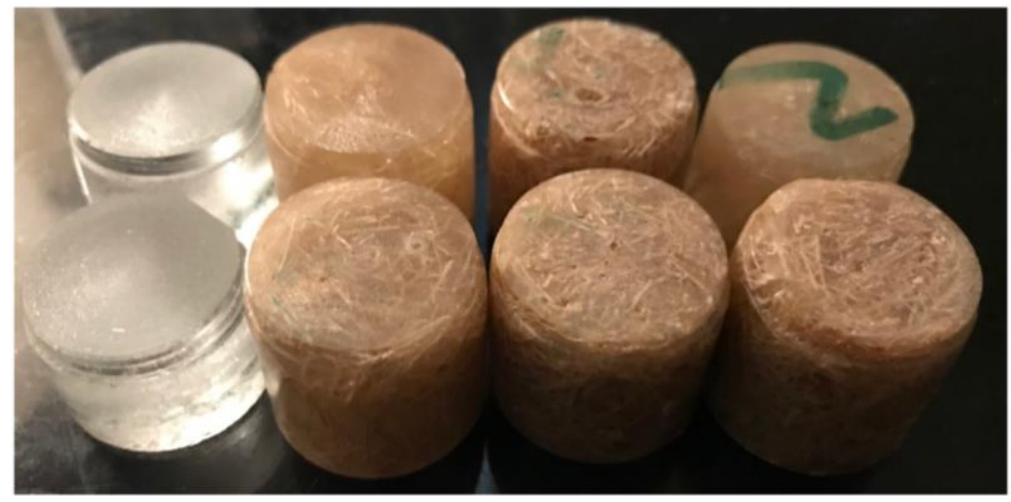

Fig. 6: Compression testing samples

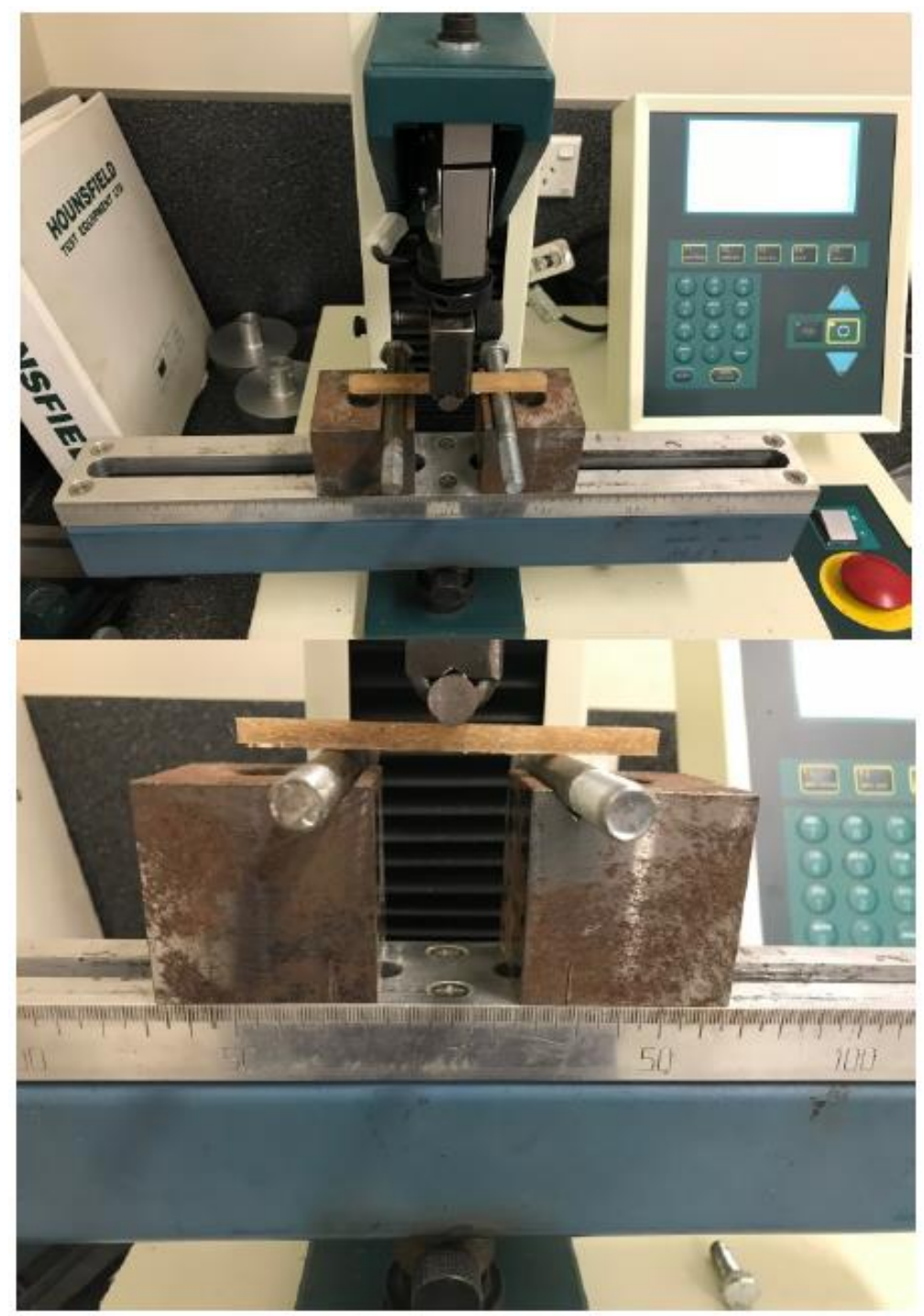

Fig. 7: Photos showing the flexural testing performed on the samples 


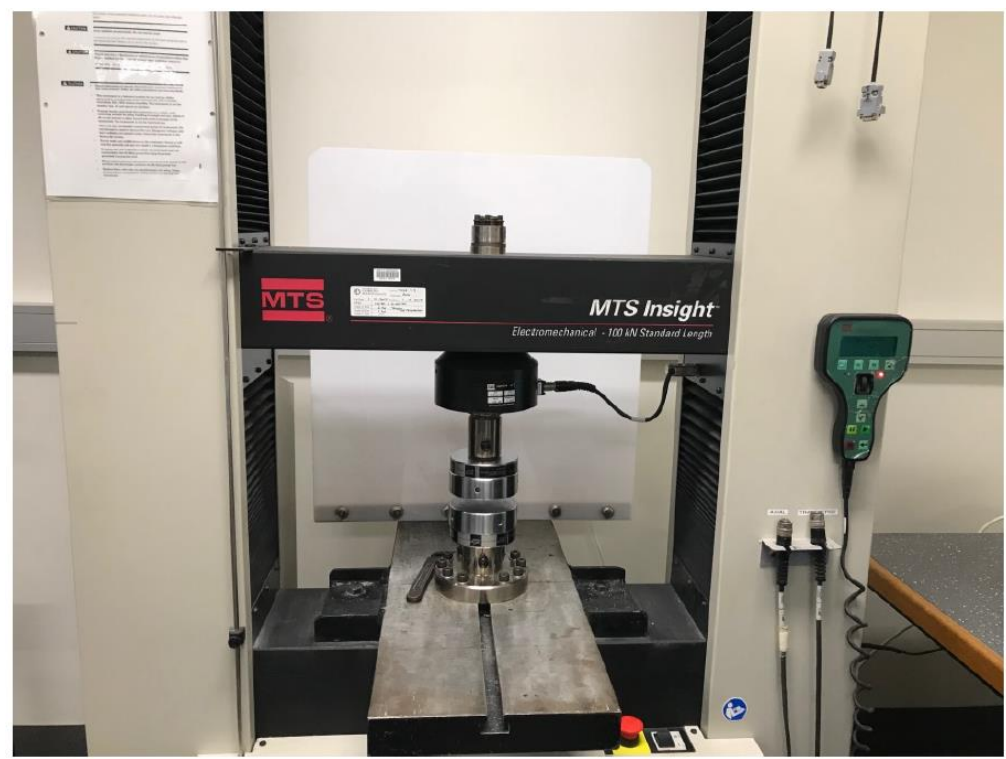

Fig. 8: Photos showing the compressive testing performed on the samples

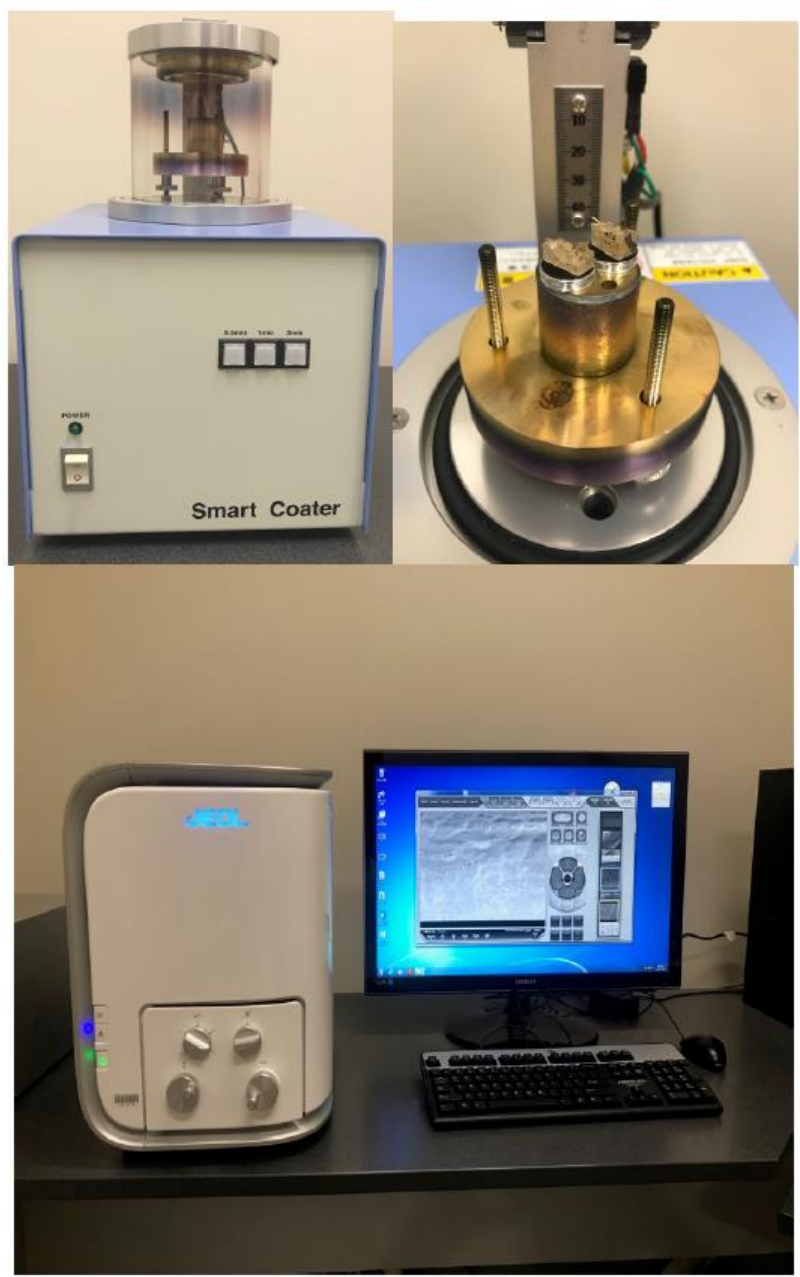

Fig. 9: SEM machines and smart coater 


\section{Scanning Electron Microscopy (SEM)}

The surfaces that are fractured of the composite specimens were examined using a Scanning Electron Microscope (SEM). Washing of the samples is done thoroughly, they are then air-dried and are then coated with a smart coater machine as shown in Fig. 9. Joel SEM desktop was used for the SEM examination. Each fractured surface was examined and few micrographs were captured.

\section{Results and Discussion}

It has been mentioned before that the coconut fibres were treated with bleaching. Figure 10 shows the micrographs of the coconut fibres before treatment and it seems there are substances attached to the surface of the fibres. Rout et al. (2001) reported that such substance is a waxy layer covering the coconut fibres. Removing such layer is very important to create a good bond between the fibre and the epoxy during the composite manufacturing process. After the coconut fibres were treated with $50 \%$ bleaching solution, the micrographs of the treated surface are presented in Fig. 11. It seems that the effect of the belching is obvious since a large amount of the waxy layer is removed. Exposure to the core of the fibres is evidence. Similar results have been reported by Libo $e t$ al. (2016) with the $\mathrm{NaOH}$ treatment. It can confirm that the first objective of the current study is achieved.

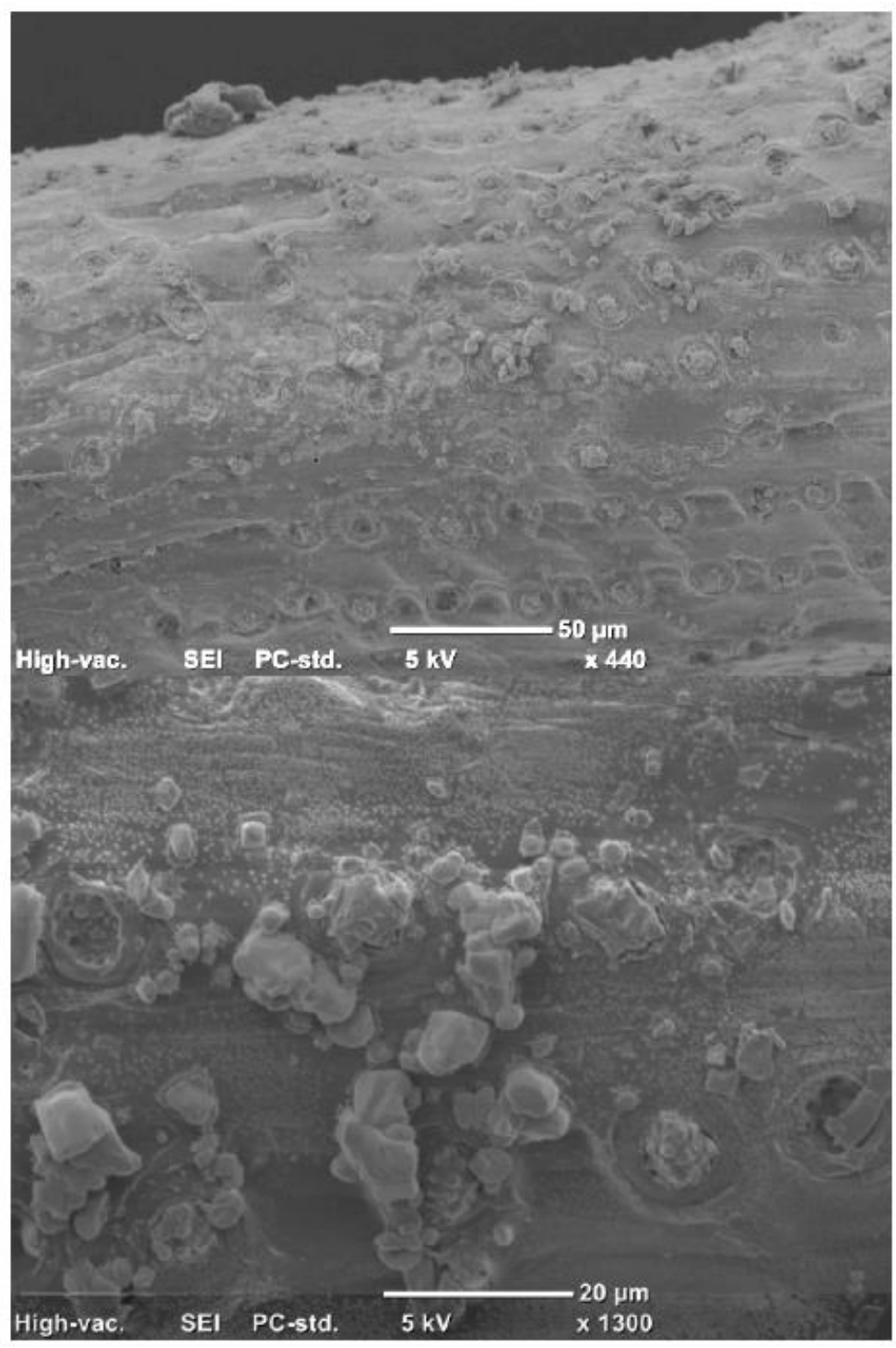

Fig. 10: micrographs of untreated coconut fibres 


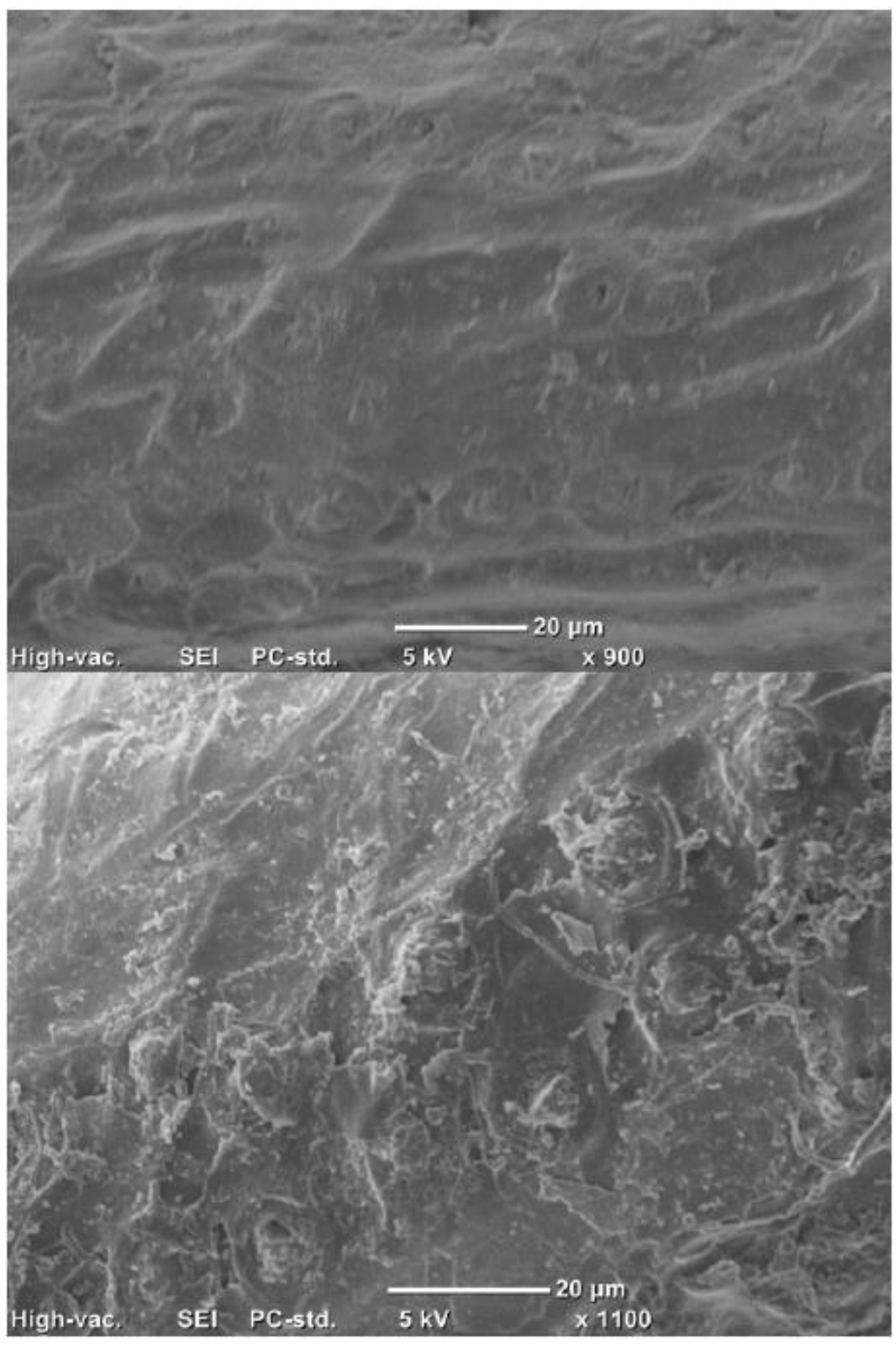

Fig. 11: micrographs of treated coconut fibres

\section{Flexural Characteristics of the Coconut/Epoxy Composites}

The flexural tests were conducted using a three-point configuration bending mechanism. The raw date was a force Vs. deformation. Stress was determent and the results are presented as stress Vs. Deformation as displayed in Fig. 12 for the four materials as pure epoxy, 10\% coconut/Epoxy, 30\% coconut/Epoxy and $40 \%$ coconut/Epoxy composites as labelled. For the pure epoxy, the brittle nature behaviour is very clear since there is elastic deformation and the plastic deformation is complete absent. The strength of the epoxy seems to be very low which is about $8.5 \mathrm{MPa}$, it should be mentioned here that the type of epoxy used in the work is for surface coating and specifically for the floor surfaces. Strengthen the epoxy can be very good for the industries especially when severe loading condition would be subjected to the surface. With 10 vol. \% coconut fibre in epoxy composites, the composite behaviour differently than the pure epoxy. There is a plastic deformation exhibited and the strength of the composites increased up to $30+\mathrm{MPa}$.

In other words, the addition of the $10 \%$ coconut fibre improves the epoxy strength by more than 3 folds. Increase the content of the fibre further to $30 \%$ shows 
less improvement compared to the $10 \%$ of coconut fibres. Up $40 \%$ of fibre content in the epoxy composites showed a further increase in the strength of the composites. $40 \%$ of coconut fibre in the composite is the maximum amount attempted in the fabrication process since it became very difficult to increase the volume fraction in the allocated cavity as you would be seen in Fig. 5. to show the effect of the volume fraction on the strength of the epoxy, Fig. 12 is developed which indicate that the maximum strength can be achieved at a high volume fraction of the coconut fibre int eh composites.

The flexural modulus of the coconut/epoxy composites is presented in Fig. 14. The figure shows that the increase in the volume fraction of the fibres in the composites increases the modulus. This is a good and promising results for the composites.
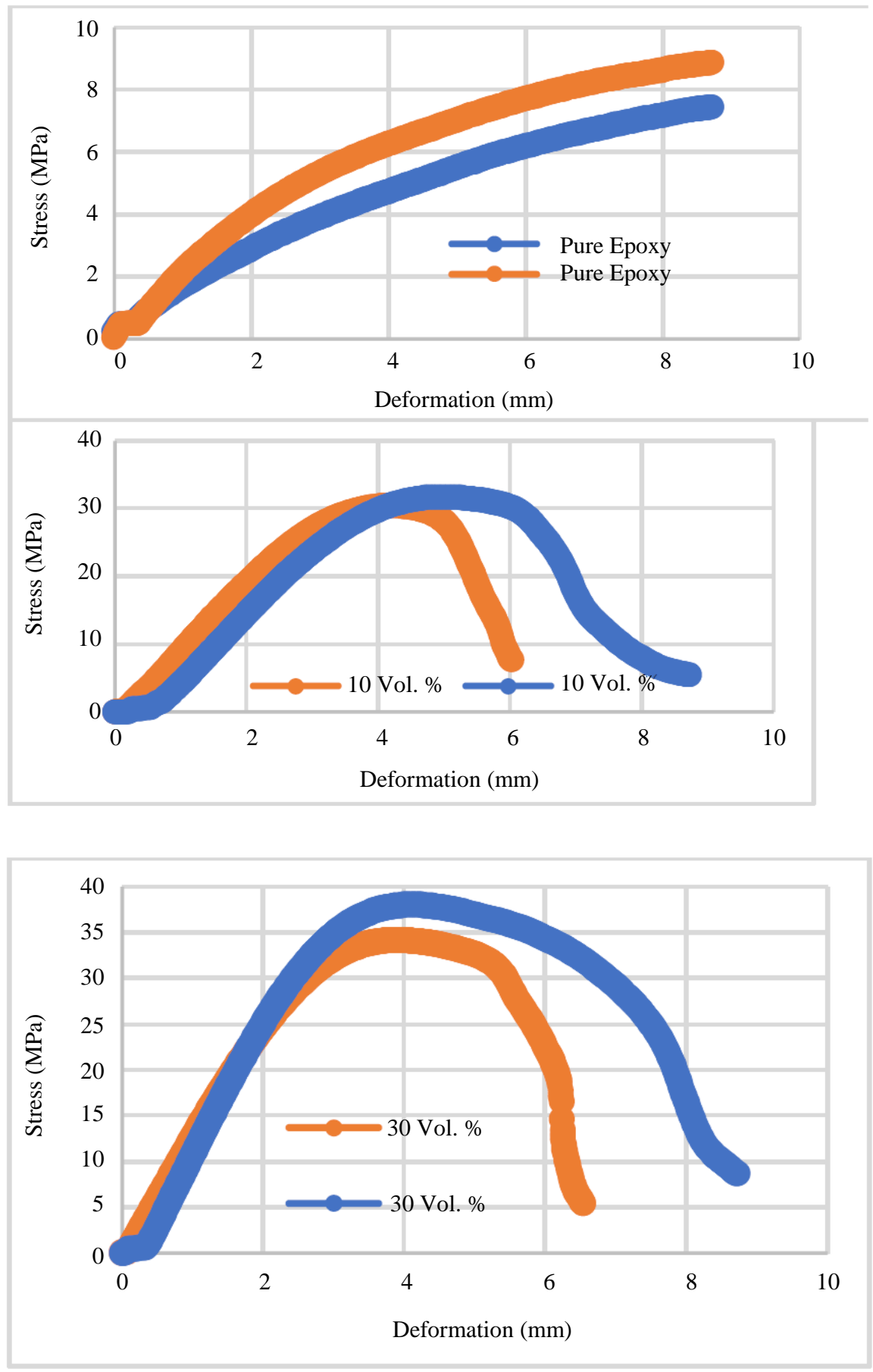


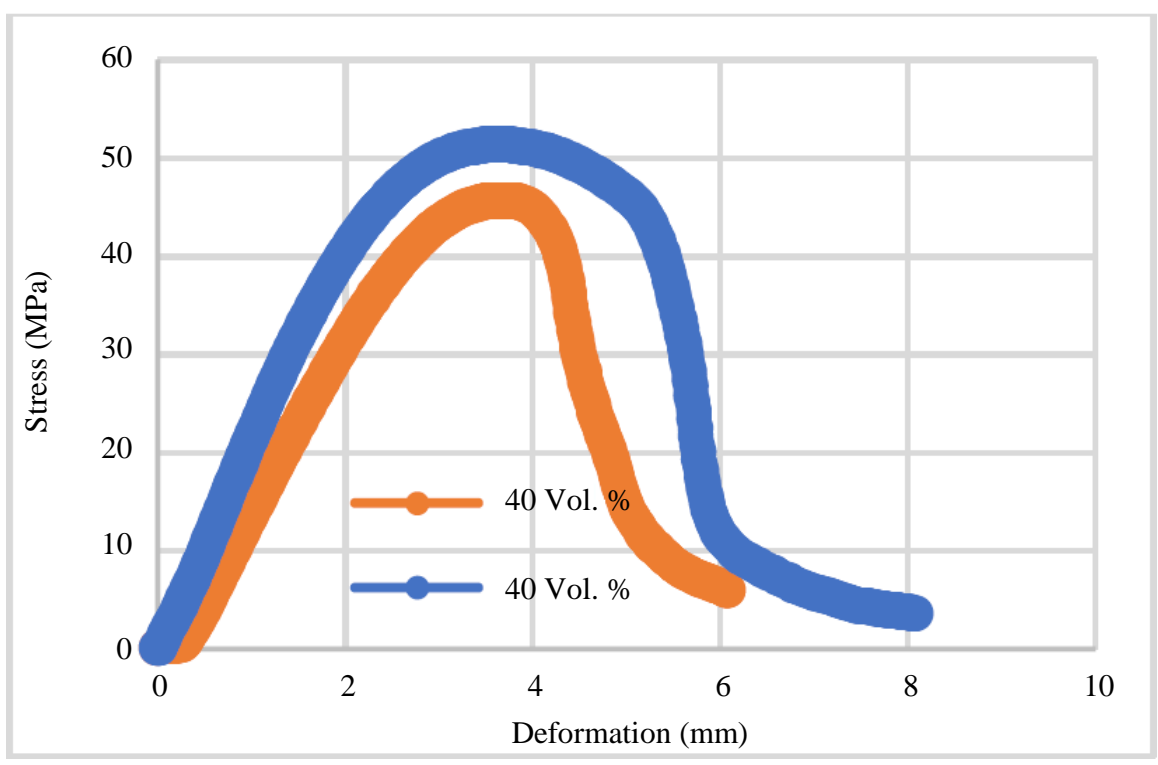

Fig. 12: flexural stress Vs. deformation of coconut/epoxy composites, two curves for the same set of test

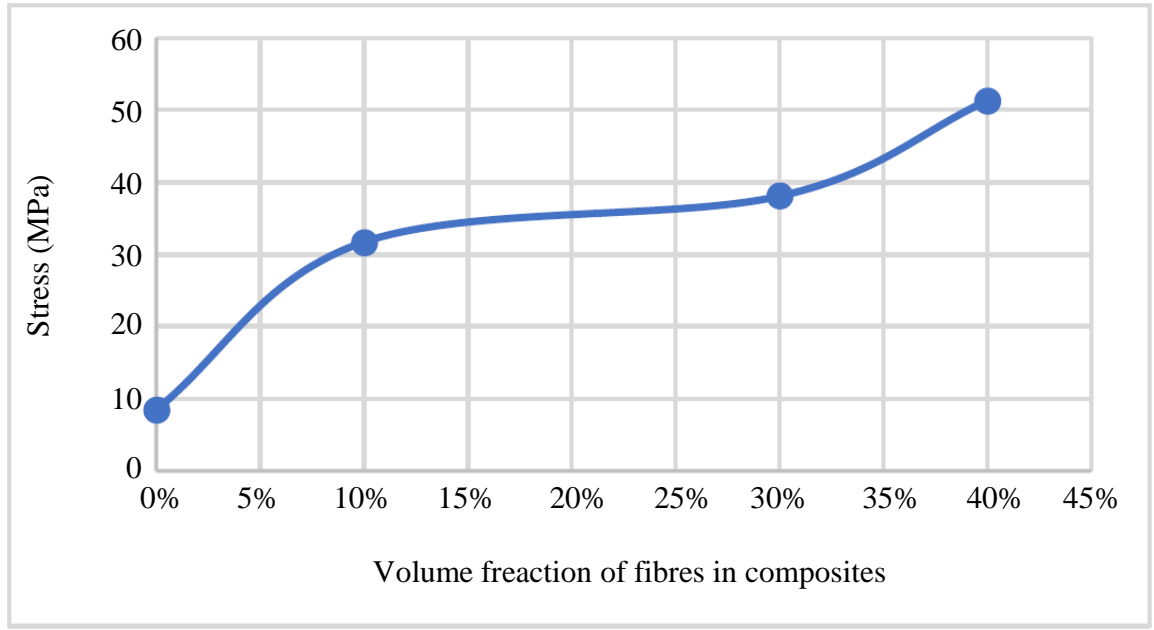

Fig. 13: Strength of coconut/epoxy at a various volume fraction of coconut fibres

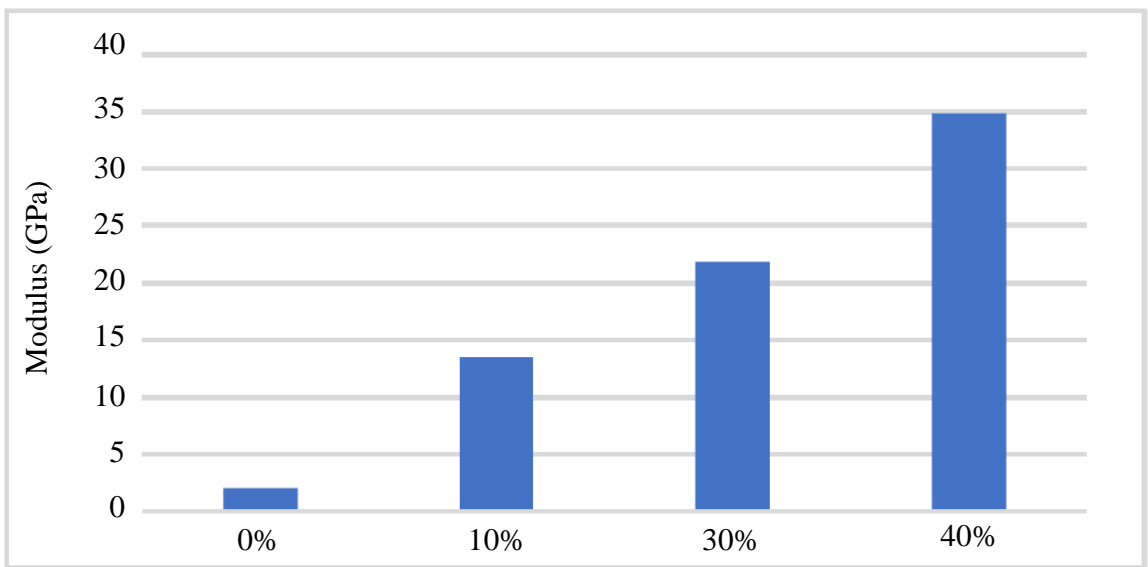

Fig. 14: Coconut fibre reinforced epoxy modulus with different volume fractions 


\section{Compressive Characteristics of Coconut/Epoxy Composites}

The compressive results of coconut/epoxy with the different volume fraction of coconut in the composites are presented in Fig. 15 to 18 as stress (MPa) vs, deformation $(\mathrm{mm})$. It was difficult to add the axial title since the date which too much and the computer was freezing during the processing of the data. In Fig. 13 the pure epoxy shows typical brittle behaviour which is similar to the flexural behaviour shown in the previous section. There is no plastic deformation presence when the pure epoxy was subjected to compressive loading condition. The strength of the epoxy is about $7 \mathrm{MPa}$. Addition 10\% of coconut fibres shows a slight improvement to the strength of the epoxy composites since there is a slight increase in the strength of the epoxy (about 9 $\mathrm{MPa}$ ). Further increase in the content of the coconut fibre in the composites exhibited dramatical enhancement to the strength of the composite since the strength reached up to $75 \mathrm{MPa}$.

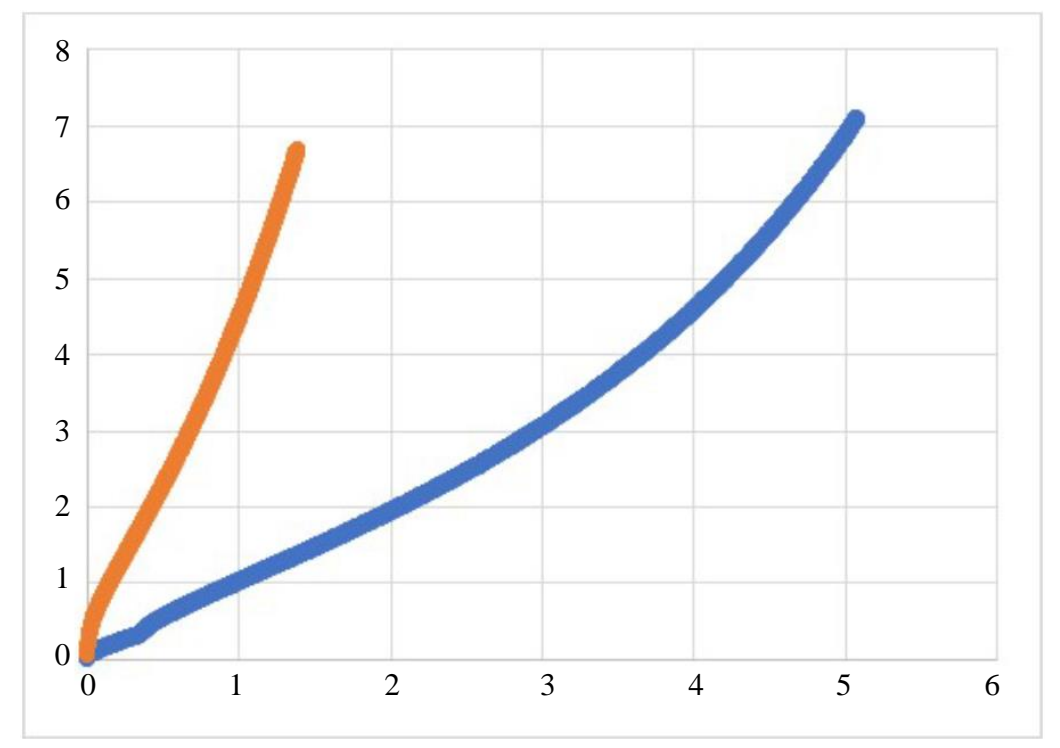

Fig. 15: Stress (MPa) Vs. deformation of pure epoxy under compressive loading condition, two curves for the same set of test

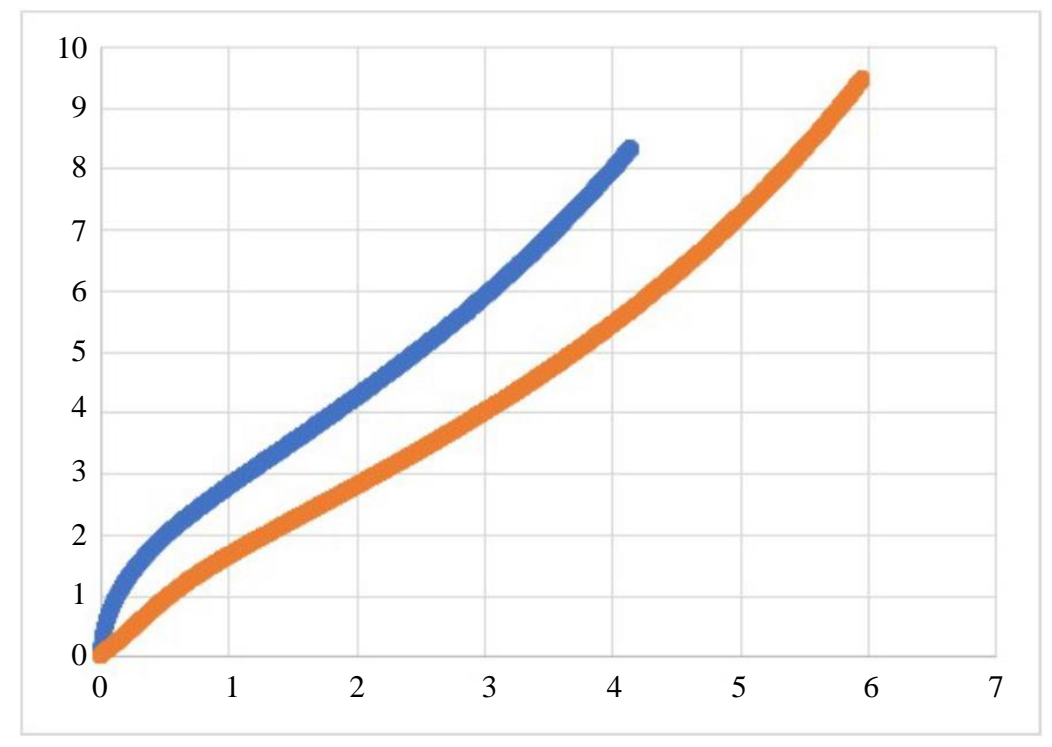

Fig. 16: Stress (MPa) Vs. deformation of 10 Vol. \% coconut/epoxy composite under compressive loading condition, two curves for the same set of test 


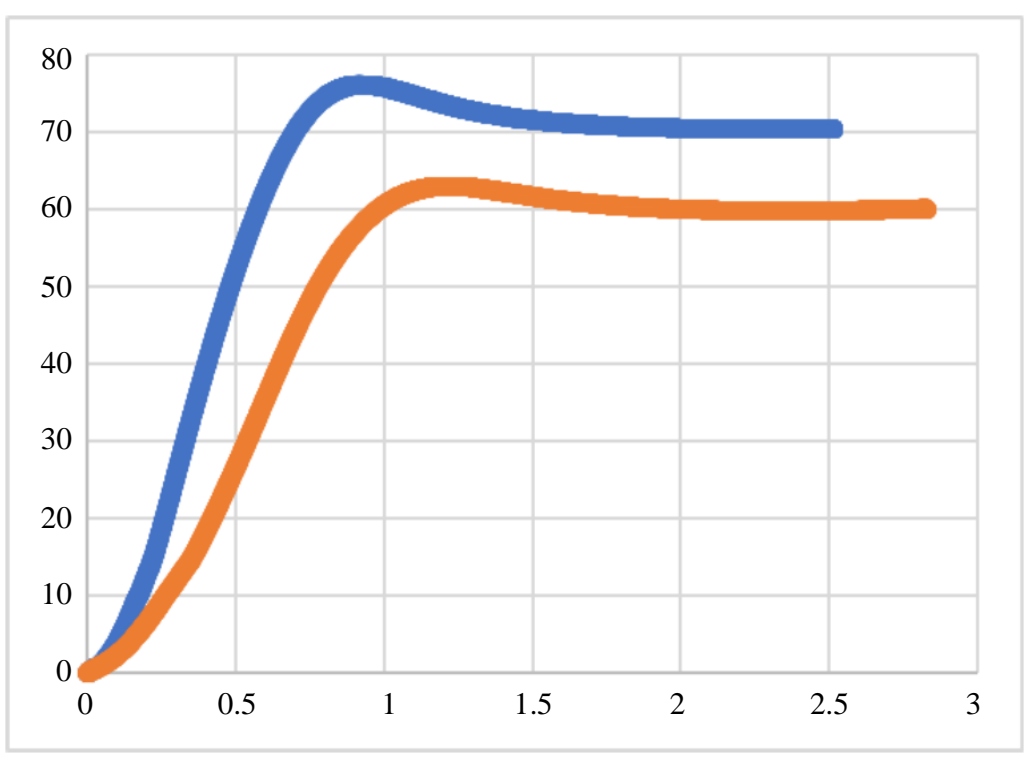

Fig. 17: Stress (MPa) Vs. deformation of 30 Vol. \% coconut/epoxy composite under compressive loading condition, two curves for the same set of test

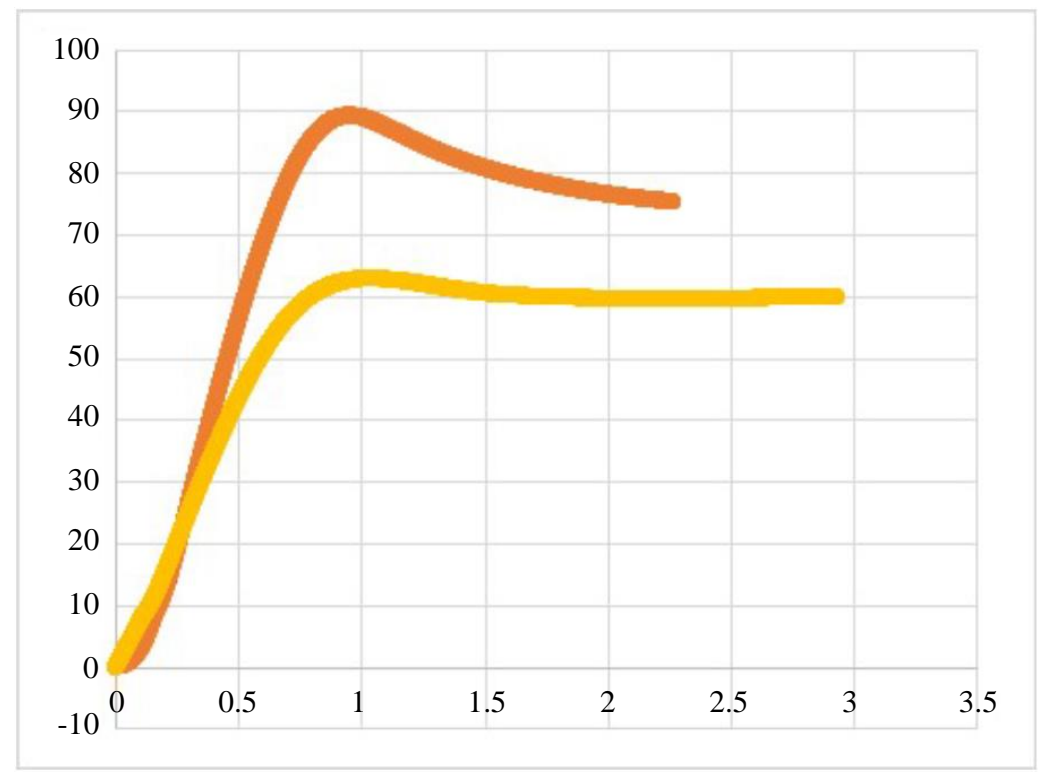

Fig. 18: Stress (MPa) Vs. deformation of 40 Vol. \% coconut/epoxy composite under compressive loading condition, two curves for the same set of test

\section{SEM Observation on the Fractured Surfaces}

Micrographs of the coconut/epoxy composites with different volume fibre fractions are displayed in Fig. 19 to 22. In general, there are a clear brittle fracture in the epoxy regions, pull out and breakage int eh fibre regions for all the samples. With the increase of the volume fraction, the severe brittleness of the composites starts to disappear. At low volume fraction, there is clear riverlike fracture mechanism which represents the severe brittle fracture. Such behaviour does not appear at high volume fraction. However, at high volume fraction, a detachment of the fibre is clear due to the shortage of resin in the composites. Despite that, there is a good bond between the fibres and the matrix since there is breakage in the fibres which indicate that the fibres were carrying the load during the flexural testing. 


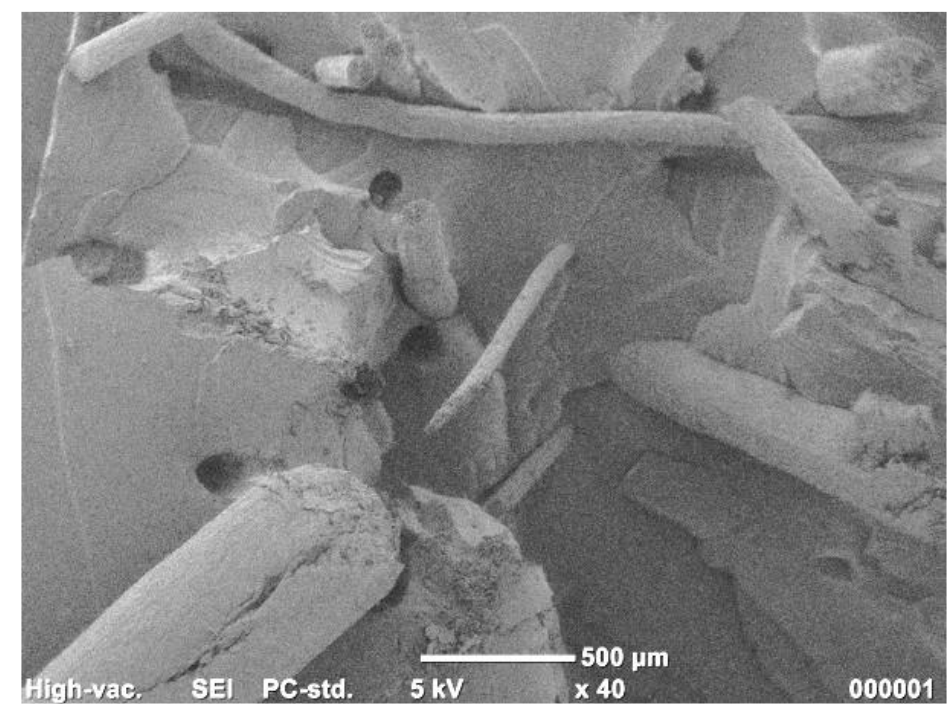

Fig. 19: Micrographs of $10 \mathrm{Vol} . \%$ coconut/Epoxy composites after flexural testing

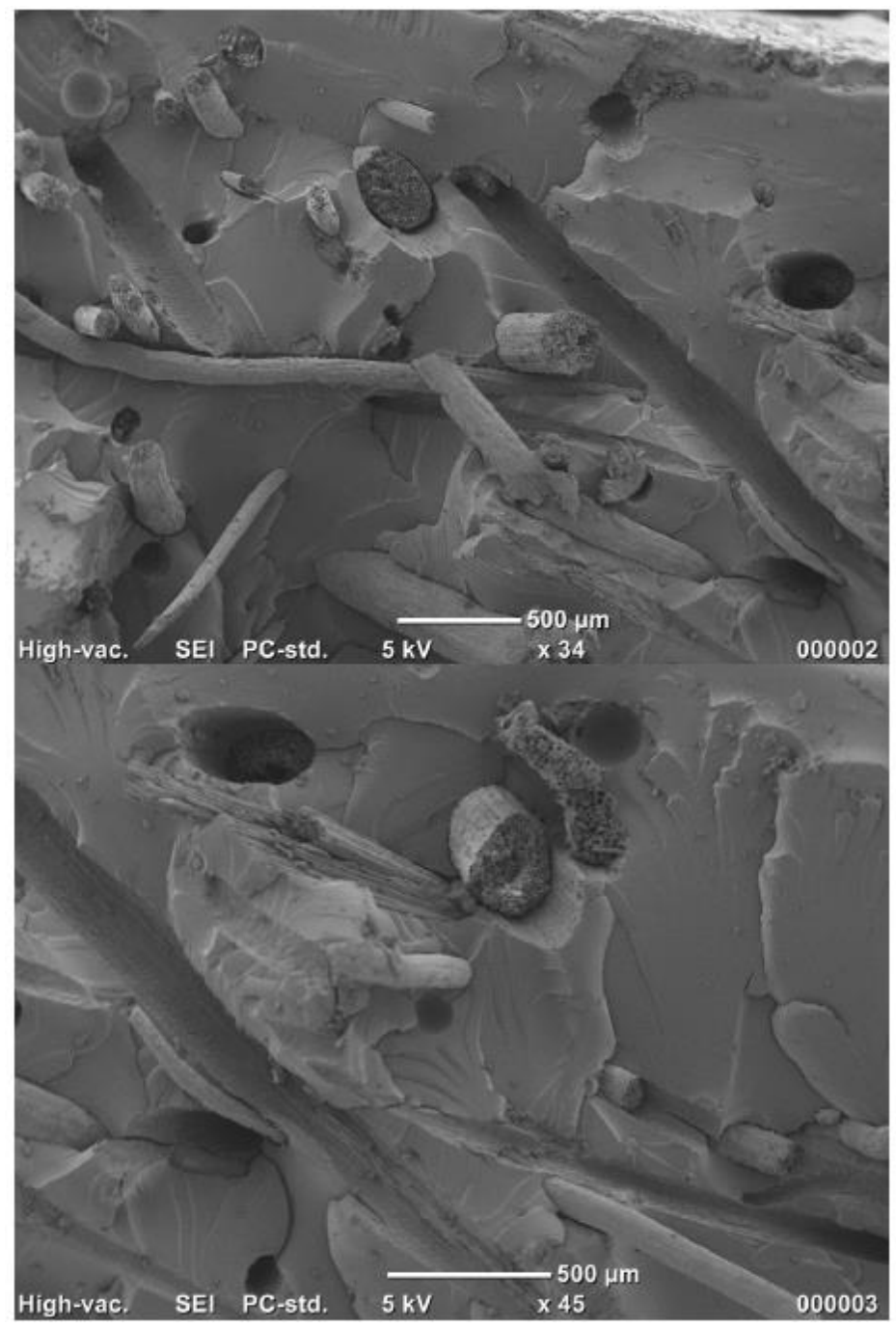

Fig. 20: Continue micrographs of $10 \mathrm{Vol}$ \% coconut/Epoxy composites after flexural testing 


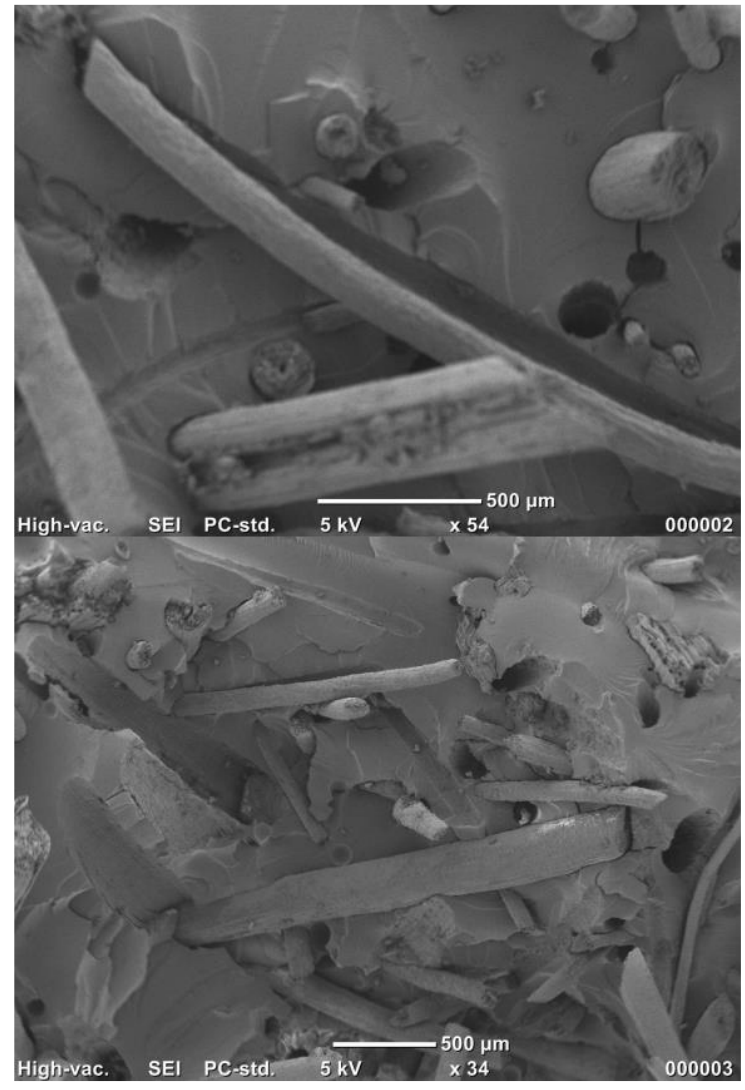

Fig. 21: Micrographs of $30 \mathrm{Vol}$ \% coconut/Epoxy composites after flexural testing

\section{Failure Mechanisms and Comparison with Reported Works}

From the results presented in the previous sections, the failure mechanism can be categorized into mainly two type which are either fracture in the resin region or damages to the fibres. The damages in the fibres were either breakage or pullout. In addition, there are some cracks were initiated close to the fibre regions which can be the weak point resulting int eh failure of the composites.

Yan et al. (2016) conducted similar results on the same type of composites of $\mathrm{NaOH}$ treated coconut fibre/epoxy composites. The damages and the failure of the composites shown to be similar to the ones presented in this project. The influence of the chemical treatment by either bleaching or $\mathrm{NaOH}$ has a similar impact on the structure and results of the composites. In recent work by Prajapati et al. (2018), the nature of the failure of the composite under tensile loading conditions is similar to the flexural. However, in that work, glass fibres were added to the composites owing to strengthen it further. In comparing the current findings and the one presented in that work, the strength in of the composites in the current study is less than the one presented in (Prajapati et al., 2018). However, the main aim of using natural fibres in the composite is to develop a

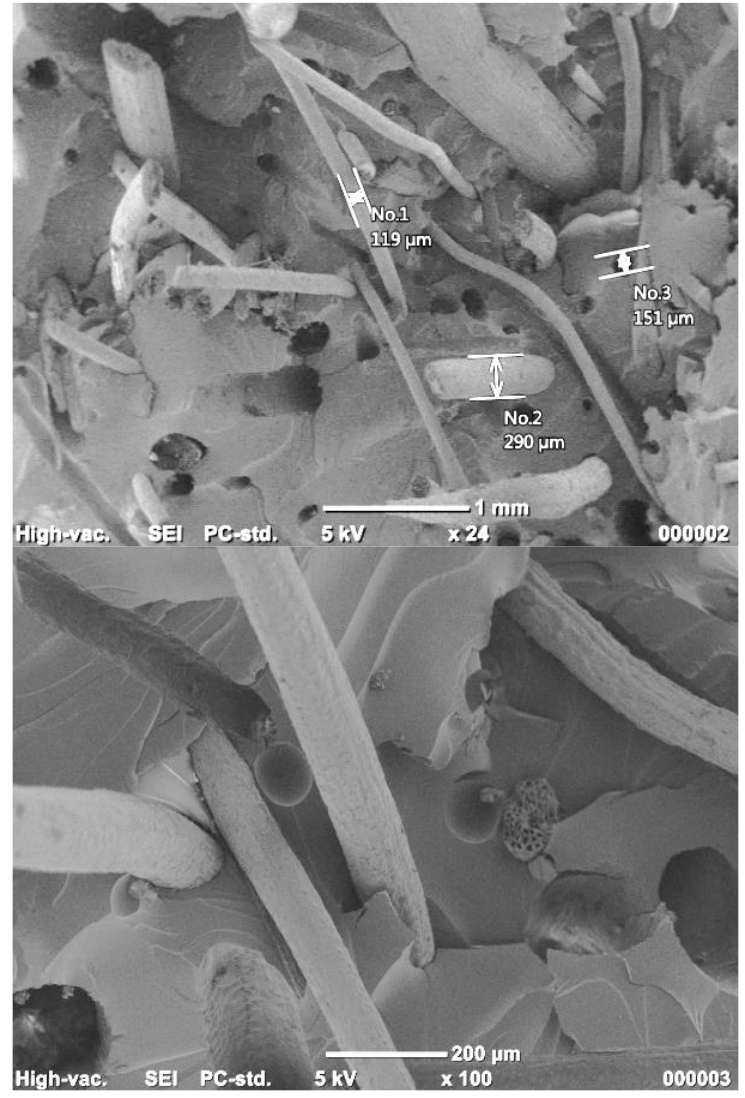

Fig. 22: Micrographs of 40 Vol. \% coconut/Epoxy composites after flexural testing

friendly composite non harming to the environment which is missing in that work since adding the glass fibres does not achieve the current trend and aim. Potadar and Kadam (2018) used shell coconut in developing composites. In that work, the strength of the composites was about 20 $\mathrm{MPa}$ only. Adding the coconut particle seems to be less effective than the fibres as seen in the current findings since the strength reached up to $40 \mathrm{MPa}$. The reason for the low performance of the composites with the coconut particle is the lake of the bonding between the particles and the resin. Also, the surface area exposure of the particles to the resin is less than the fibres. Tran et al. (2015) studied the effect of the coconut fibre length on the mechanical properties of epoxy composites. That work confirms that $10 \mathrm{~mm}$ fibre length is the optimum fibre length which is used in the current study. At a long length of fibres, there was a slight reduction in the strength of the composites as reported by that work.

\section{Conclusion}

This project aimed to study the influence of the coconut fibres on the epoxy composites properties considering different fibre volume fractions. The following conclusion can be given as: 
1. Brittle failure is the main damage feature in the pure epoxy

2. Bleaching the coconut fibre significantly improves the surface characteristics of the coconut fibres which results in a good bond between the fibre and the epoxy

3. Reinforces epoxy with coconut fibre strengthen the epoxy by about $300 \%$

4. Treating the fibres with bleach showed similar effects as the $\mathrm{NaOH}$ treatment

5. Ductility of the composites significantly enhanced with the addition of the fibres

6. The high volume fraction of the coconut fibres in the epoxy composites showed good improvement to the strength of the composites under both flexural and compressive loadings

\section{Author's Contributions}

Jasem G. Alotaibi: Results analysis and critical arguments with the literature and contribute to the introduction to draw the motivation of the work.

Ayedh Eid Alajmi: Assist in the methodology and experimental done

Belal F. Yousif: Overview writing and organization of the article.

Nbhan D. Salih: Contribute to the drawing of the conclusion and identify the main contribution to the literature.

\section{Ethics}

This article is original and contains unpublished material. The corresponding author confirms that all of the other authors have read and approved the manuscript and no ethical issues involved.

\section{References}

Bongarde, U.S. and V.D. Shinde, 2014. Review on natural fiber reinforcement polymer composites. Int. J. Eng. Sci. Innov. Technol.

Espinach, F.X., S. Boufi, M. Delgado-Aguilar, F. Julián and P. Mutjé et al., 2018. Composites from poly (lactic acid) and bleached chemical fibres: Thermal properties. Composites Part B: Eng., 134: 169-176. DOI: 10.1016/j.compositesb.2017.09.055

Hamidon, M.H., M.T.H. Sultan, A.H. Ariffin and A.U.M. Shah, 2019. Effects of fibre treatment on mechanical properties of kenaf fibre reinforced composites: A review. J. Mater. Res. Technol., 8: 3327-3337. DOI: 10.1016/j.jmrt.2019.04.012

Hedayati, E. and M. Vahedi, 2017. Numerical investigation of penetration in ceramic/aluminum targets using smoothed particle hydrodynamics method and presenting a modified analytical model. Comput. Model. Eng. Sci., 113: 295-323.
Hedayati, E. and M. Vahedi, 2018. Evaluating impact resistance of aluminum 6061-T651 plate using smoothed particle hydrodynamics method. Defence Sci. J., 68: 251-259. DOI: 10.14429/dsj.68.11635

Indra Reddy, M., M. Anil Kumar and C.H.R. Bhadri Raju, 2018. Tensile and Flexural properties of Jute, Pineapple leaf and glass fiber reinforced polymer matrix hybrid composites. Mater. Today: Proc., 5: 458-462. DOI: 10.1016/j.matpr.2 017.11.105

Libo, Y., N. Chouw, L. Huang and B. Kasal, 2016. Effect of alkali treatment on microstructure and mechanical properties of coir fibres, coir fibre reinforced-polymer composites and reinforced-cementitious composites. Construc. Buil. Mater., 112: 168-182.

DOI: 10.1016/j.conbuildmat.2016.02.182

Omrani, E., P.L. Menezes and P.K. Rohatgi, 2016. State of the art on tribological behavior of polymer matrix composites reinforced with natural fibers in the green materials world. Eng. Sci. Technol. Int. J., 19: 717-736. DOI: 10.1016/j.jestch.2015.10.007

Potadar, O.V. and G.S. Kadam, 2018. Preparation and testing of composites using waste groundnut shells and coir fibres. Proc. Manuf., 20: 91-96. DOI: 10.1016/J.PROMFG. 2018.02.013

Prajapati, P., C. Sharma, R. Shrivastava and R.S. Rana, 2018. Evaluation of mechanical properties of coir and glass fiber hybrid composites. Mater. Today: Proc., 5: 19056-19062. DOI: 10.1016/J.MATPR.2 018.06 .258

Rout, J., M. Misra, S.S. Tripathy, S.K. Nayak and A.K. Mohanty, 2001. The influence of fibre treatment on the performance of coir- polyester composites. Comp. Sci. Technol., 61: 1303-1310. DOI: 10.1016/S0266-3538(01)00021-5.

Supian, A.B.M., S.M. Sapuan, M.Y.M. Zuhri, E.S. Zainudin and H.H.J. Ya, 2018. Hybrid reinforced thermoset polymer composite in energy absorption tube application: A review. Defence Technol., 14: 291-305. DOI: 10.1016/j.dt.2018.04.004

Tran, L.Q.N., T.N. Minh, C.A. Fuentes, T.T. Chi and A.W. Van Vuure et al., 2015. Investigation of microstructure and tensile properties of porous natural coir fibre for use in composite materials. Industrial Crops Products, 65: 437-445. DOI: $10.1016 /$ J.INDCROP.2014.10.064

Yan, L., N. Chouw, L. Huang and B. Kasal, 2016. Effect of alkali treatment on microstructure and mechanical properties of coir fibres, coir fibre reinforcedpolymer composites and reinforced-cementitious composites. Constr. Build. Mater., 112: 168-182. DOI: 10.1016/j.conbuildmat.2016.02.182 